\title{
Factors Predicting Mortality of Acute Variceal Bleeding in Liver Cirrhosis
}

\author{
Amrendra Kumar Mandal,, ${ }^{1}$ Mukesh Sharma Paudel, ${ }^{1}$ Sudhamshu KC, ${ }^{2}$ Sitaram Chaudhary, ${ }^{1}$ Bidhan Nidhi

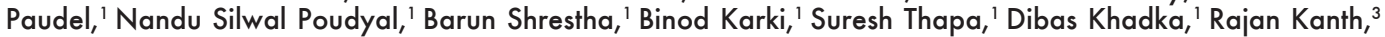 \\ Paritosh Kafle ${ }^{4}$ \\ 'Gastroenterology Unit, Department of Medicine, Bir Hospital, NAMS, Kathmandu, Nepal, ${ }^{2}$ Hepatology Unit, Department of \\ Medicine, Bir Hospital, NAMS, Kathmandu, Nepal, ${ }^{3}$ Carilion Clinic, VA, USA, ${ }^{4}$ Interfaith Medical Center, Brooklyn, NY, USA.
}

\section{ABSTRACT}

Introduction: Acute variceal bleeding in liver cirrhosis is an immediate life-threatening condition and amajor complication of portal hypertension associated with higher morbidity, mortality and hospital costs than any other causes of UGI bleeding. Therefore, early stratification and initiation of therapy based on several factors can reduce mortality associated with it. We aimed to study the predictors of mortality in acute variceal bleeding in LC.

Methods: An observational prospective study was conducted in Gastroenterology and Hepatology units of Bir Hospital, Kathmandu, Nepal from April 1, 2016 to May 30, 2017. Patients were included if they had underlying liver cirrhosis and presented upper GI bleeding which were proven to be secondary to variceal bleeding.

Results: Seventy-five patients with mean age of 52.5 years were available or the analysis. The M:F ratio was 2.1:1. There were 66 patients in mortality group and 9 in survivor group. The mean CTP and MELD score were $10.17 \pm 1.66$ and $20.40 \pm 8.29$ respectively. Among the predictors of the mortality studied, CTP score, MELD score, mean arterial pressure, Serum bilirubin, serum creatinine, need of FFP as well as PRP transfusion, presence of hepatorenal syndrome and hepatic encephalopathy were high in mortality group with statistical significance. On multivariate analysis, high CTP and high serum creatinine level were only significant predictors of mortality. Receiver operating curve for predicting accuracy of mortality was significant with higher MELD and higher CTP score.

Conclusions: Strong predictors of mortality in patients with cirrhosis presenting with variceal bleeding are CTP score and high serum creatinine level.

Keywords: acute variceal bleeding; CTPscore; MELD score; serum creatinine.

\section{INTRODUCTION}

Acute variceal bleeding is an immediate life-threatening major complication of portal hypertension associated with higher morbidity, mortality and hospital costs. It occurs at a yearly rate of $5 \%-15 \%$ in cirrhotic patients. ${ }^{1}$ The most important predictor of bleeding is the size of thevarices, with the highest risk of first bleeding $(15 \%$ per year) occurring in patients with large varices. ${ }^{2} \mathrm{Up}$ to $25 \%$ of the patients with newly diagnosed varices will experience variceal bleeding within two years. ${ }^{3}$

Approximately $30 \%-50 \%$ of patients with liver cirrhosis (LC) die within six weeks of the first variceal bleeding episode. ${ }^{4}$ While most patients with cirrhosis form varices at some point in their disease. However, only one third will bleed among them.

The aim of the study was to find the factors associated with mortality in patients with LC presenting as acute variceal bleeding at tertiary care hospital.

Correspondence: Dr. Amrendra Kumar Mandal Gastroenterology Unit, Bir Hospital, NAMS, Kathmandu, Nepal. Email dr.akmandal@yahoo.com. Phone: +977-9851247755. 


\section{METHODS}

This was an observational prospective study. It was conducted at Bir Hospital, NAMS (National Academy of Medical Sciences), Kathmandu, Nepal from April 1, 2016 to May 30, 2017. Ethical approval was taken from the Institutional Review Board (IRB) of the Bir Hospital, NAMS.

Consecutive patients of upper gastrointestinal (UGI) bleeding (hematemesis, coffee ground vomitus, hematochezia, or melena) were subjected to endoscopic evaluation after stabilization of hemodynamics. All patients with bleeding varices were included inthe study. Non-cirrhotic portal hypertensive patients, patients aged less than 18 years and patients with HCC or other co-morbidities were excluded. Packed red cell transfusion was done to maintain the haemoglobin level between 8-9 $\mathrm{mg} / \mathrm{dL}$. Platelets rich plasma and fresh frozen plasma were transfused whenever required and required units were noted. All the basic investigations were obtained to calculate CTP and MELD score. After stabilization, Pantoprazole $40 \mathrm{mg}$ IV loading dose followed by 8 mgper hour was infused, IV Octreotide $50 \mathrm{mcg}$ loading dose followed by $50 \mathrm{mcg}$ per hour was infused for 5 days. All patients underwent UGI endoscopy followed by endoscopic variceal ligation
(EVL). All causes of in-hospital mortality were recorded. The patients were divided into survivor and mortality groups and different variables were compared.

Minimum required sample size for this study was calculated by the formula,

$\mathrm{N}=(\mathrm{Za} 2)(\mathrm{P})(\mathrm{Q}) / \mathrm{d} 2$.

Where, $\quad \mathrm{N}=$ required sample size, $\mathrm{Za}=$ Variate corresponding to desired reliability level 11.96 for $95 \%$ reliability), $\mathrm{P}=$ Estimated proportion in the population ( $5 \%$ for this study) ${ }^{2}, Q=100-P$ (if $P$ is in $\%$ ) and $d=$ Maximum tolerable error $(5 \%)$. With this formula minimum required sample size was 72 .

\section{RESULTS}

A total of 97 patients presented with variceal bleeding within the study period. 22 patients were excluded, and the cause of exclusion were non-cirrhotic portal fibrosis related bleed $(n=7)$, extra-hepatic portal obstruction $(n=9)$, patients aged under $18(n=6)$. Finally,75 patients were available for the analysis. There was male preponderance with $M$ : Fratio of $2.1: 1$. The mean age of the patients was 52.5 year.There were 9 deaths during the study period. The baseline characteristics of the study population are shown (Table 1).

\begin{tabular}{|llll|}
\hline Table 1. Baseline characteristics of the study. & & \\
\hline Characteristics & Mortality $(\mathbf{n}=\mathbf{9})$ & Survivors $(\mathbf{n}=66)$ & P value \\
& Mean \pm SD & Mean \pm SD & 0.19 \\
Age(years) & $55.54 \pm 11.68$ & $49.48 \pm 13.03$ & $<0.01$ \\
Blood pressure (mm Hg) & $88.56 / 55.44 \pm 16.67 / 13.33$ & $103.4 / 66.12 \pm 21.45 / 9.91$ & 0.68 \\
Hemoglobin (gm/dL) & $8.18 \pm 2.03$ & $8.59 \pm 2.89$ & 0.3 \\
Platelet//mm $\left.{ }^{3}\right)$ & $81111.00 \pm 43613.20$ & $106300 \pm 70248.48$ & 0.08 \\
AST(IU/mL) & $172.78 \pm 187.70$ & $89.80 \pm 66.41$ & 0.01 \\
Bilirubin (mg/dL) & $8.96 \pm 5.91$ & $5.10 \pm 6.83$ & 0.14 \\
Alkalaine phosphatase(IU/mL) & $146.44 \pm 92.23$ & $113.39 \pm 54.01$ & 0.59 \\
INR & $1.82 \pm 0.58$ & $1.72 \pm 0.63$ & 0.86 \\
Albumin(g/dL) & $2.50 \pm 0.66$ & $2.54 \pm 0.59$ & 0.25 \\
Urea(mg/dL) & $141.22 \pm 60.50$ & $84.08 \pm 145.53$ & 0.001 \\
Creatinine(mg/dL) & $2.96 \pm 1.42$ & $1.43 \pm 0.78$ & 0.34 \\
Na(meq/L) & $136.11 \pm 9.55$ & $133.44 \pm 7.62$ & 0.17 \\
K(meq/L) & $4.67 \pm 0.72$ & $4.23 \pm 0.90$ & \\
\hline
\end{tabular}

The mean hospital stay in the study population was 7.79 days. In the mortality group, total hospital stay was $7.11 \pm 5.75$ daysand in a survival group it was $7.88 \pm 4.32$ days $(P=0.63)$. The study population according to CTP score was as follows: CTP-A was 4 (5.33\%), CTP-B was 25 (33.33\%) and CTP -C was 46 (61.33\%). The mean CTP score in a study population was $10.17 \pm$ SD 1.66 whereas the mean MELD score was $20.40 \pm 8.29$. The comparisons of predictors of mortalityin non-survivors (mortality) and in survivors are 
shown (Table 2).

\begin{tabular}{|c|c|c|c|}
\hline Variables & Mortality & Survival & $P$ value \\
\hline CTP score & $11.56 \pm 1.67$ & $9.98 \pm 1.57$ & 0.007 \\
\hline $\begin{array}{l}\text { MELD } \\
\text { score }\end{array}$ & $29.11 \pm 4.99$ & $19.21 \pm 7.95$ & 0.001 \\
\hline $\begin{array}{l}\text { Total } \\
\text { bilirubin }\end{array}$ & $8.96 \pm 5.91$ & $5.10 \pm 6.83$ & 0.01 \\
\hline $\begin{array}{l}\text { Serum } \\
\text { Creatinine }\end{array}$ & $2.96 \pm 1.42$ & $1.43 \pm 0.78$ & $<0.01$ \\
\hline $\begin{array}{l}\text { Units of } \\
\text { transfused } \\
\text { PRP }\end{array}$ & $1.67 \pm 1.0$ & $1.05 \pm 1.93$ & 0.022 \\
\hline FFP & $2.78 \pm 1.09$ & $1.36 \pm 1.06$ & $<0.001$ \\
\hline MAP & $64.89 \pm 13.59$ & $79.47 \pm 19.06$ & 0.012 \\
\hline
\end{tabular}

Using chi square test; past history of EVL $(p=0.03)$, presence of HRS $(p=0.007)$, HE (hepatic encephalopathy) $(p=0.034)$, early rebleed $(p=0)$ and co-morbidity $(p=0.007)$ were associated with significant mortality. Presence of spontaneous bacterial peritonitis (SBP) was not associated with significant mortality $(p=0.59)$ in our study population.

By multivariate analysis, higher CTP, and higher serum creatinine were an independent risk factor of in hospital mortality (Table 2).Receiver Operator Curve (ROC) for

predicting accuracy of mortality is shown (Table 4).

\begin{tabular}{|lrlll|}
\hline $\begin{array}{l}\text { Table 3. Showing } \\
\text { analysis. }\end{array}$ & multivariate logistic regression \\
\hline Variables & OR & \multicolumn{2}{l|}{$\begin{array}{l}\text { 95\% confidence } \\
\text { interval for }\end{array}$} & P value \\
& & $\begin{array}{l}\text { Lower } \\
\text { upper }\end{array}$ & \\
$\begin{array}{l}\text { Child Pugh } \\
\text { Score } \\
\text { Creatinine }\end{array}$ & 2.38 & 1.17 & 4.87 & 0.017 \\
\hline
\end{tabular}

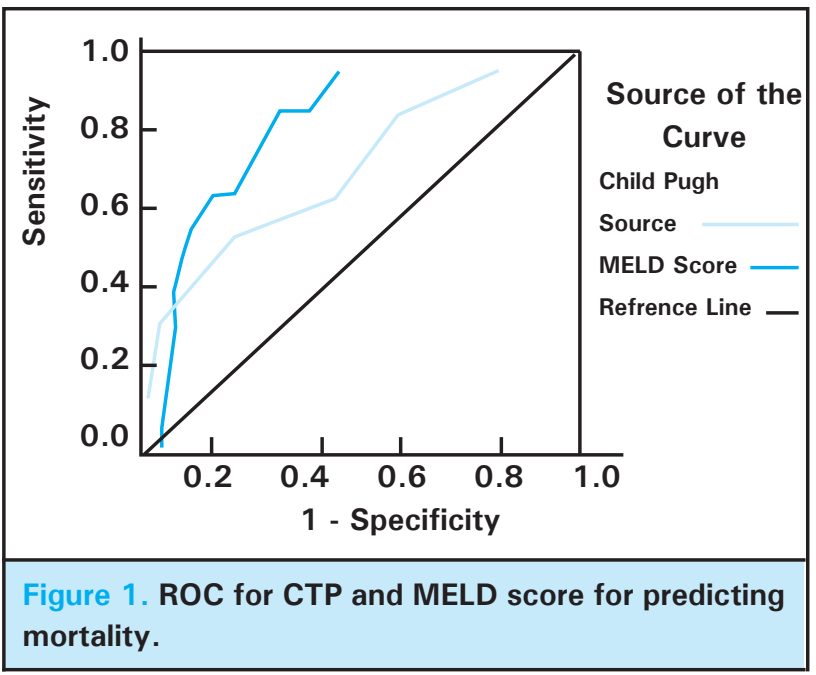

\begin{tabular}{|c|c|c|c|}
\hline Variables & Area & SE & $P$ value \\
\hline $\begin{array}{l}\text { CHILD Pugh } \\
\text { score }\end{array}$ & 0.748 & 0.088 & 0.016 \\
\hline MELD Score & 0.857 & 0.052 & 0.001 \\
\hline
\end{tabular}

\section{DISCUSSION}

The incidence of in-hospital mortality due to variceal bleeding in patients with LC was $12 \%$ in our study which is consistent with several other studies. ${ }^{5}$ In a large series of 403 patients with variceal bleeding in LC, Del Olmo et al found a mortality rate of $7.4 \%$. In different studies by several authors including Chalasaniet al, Faisal et al, Ahmed et al,Romcea et al, all of them noted in-hospital mortality of $14.2 \%, 8.7 \%, 8 \%$, and $2.93 \%$ respectively. ${ }^{6-8}$

Due to advancement in the endoscopic procedures including the recent modalities like esophageal stenting and more availability of interventional procedures like transjugular intravenous portosystemic stent shunt (TIPS), significant fall in mortality is expected over time.

In our study, the highest mortality was observed in CTP-C which was 8 (88.8\%) followed by CTP- B having one $(11.1 \%)$ death. However, no mortality was seen in CTP-A. It suggests that the degree of liver dysfunction is an important predictor of variceal bleeding and it also reflects mortality.

In our study, majority of patients presented to hospitals were more severe as evidenced by CTP- $\mathrm{C}$ in comparison to other study by Choi YJ et al where majority i.e. 273 $(42.5 \%)$ of patients were CTP-B followed by 180 (28.0\%) CTP-C. ${ }^{9}$

A MELD score $>19$ was associated with 20 percent mortality rate, while a MELD score $<11$ was associated with $<5$ percent mortality rate. ${ }^{10}$ This scoring tool is potentially useful threshold for defining a high risk of death.MELD score has also been shown to be the best predictors of mortality based on ROC in our study which is consistent witha study by Reverter et al. ${ }^{11}$

The study conducted by Faisal et al reported that the non-survivors had higher serum bilirubin (2.4 vs. 1.6 $\mathrm{mg} / \mathrm{dL} ; \mathrm{P}=0.032$ ) and serum creatinine (2.1 vs. $1.1 \mathrm{mg} /$ $d L ; P=0.02$ ) which is also consistent with our study. ${ }^{8}$

Using univariate logistic regression analysis for mortality; CTP score, MELD score, AST, Serum creatinine, transfusion of fresh frozen plasma, inotrope infusion, early re-bleed, development of HRS and HE were associated with significant mortality in our study. 
However, on multivariate logistic regression analysis, the independent predictors of mortality were noted only in higher CTP score and higher serum creatinine.

The independent predictors of mortality on multiple logistic regression analysis seen in other study were also similar to our study. ${ }^{8,12,13}$ These predictors were serum creatinine $>1.5 \mathrm{mg} / \mathrm{dL}$, serum bilirubin $>3 \mathrm{mg} /$ $\mathrm{dL}$ and presence of $\mathrm{HE}$.

We also compared CTP and MELD score for largest area under the receiver operator curve (AUROC) and the values obtained for MELD score and CTP score were 0.857 and 0.748 respectively which was also consistent with study by Mohmmad et al, where AUROC for CTP score was >0.8. ${ }^{13}$ Our study showed MELD score to be more accurate predictor of mortality as compared to CTP score.

There are some limitations of our study including small sample size; no follow up after the patients were discharged.

\section{CONCLUSIONS}

CTP-C and high serum creatinine are the two most important factors associated with mortality, but the accurate predictor of mortality was higher MELD score. These factors can be used in the resource limited setting in order to stratify the higher risk group.

\section{Conflict of Interest: None.}

\section{REFERENCES}

1. Brocchi E, Caletti G, Brambilla G, La Mantia L, Lupinacci G, Pisano G, et al. Prediction of the first variceal hemorrhage in patients with cirrhosis of the liver and esophageal varices. A prospective multicenter study. N Engl J Med. 1988;319(15):983-9. [․ubMed | Full Text]

2. GarciaTsao G, Sanyal AJ, Grace ND, Carey W. Prevention and management of gastroesophageal varices and variceal hemorrhage in cirrhosis. Hepatol. 2007;46(3):922-38. [PubMed |DOI]

3. de Franchis R, Primignani M. Natural history of portal hypertension in patients with cirrhosis. Clin Liver Dis. 2001;5(3):645-63. [PubMed]

4. McCormick P, O'keefe C. Improving prognosis following a first variceal haemorrhage over four decades. Gut. 2001;49(5):682-5. [PubMed | Full Text]

5. Sharara AI, Rockey DC. Gastroesophageal variceal hemorrhage. N Engl J Med. 2001;345(9):669-81. [PubMed |DOI]

6. del Olmo JA, Peña A, Serra MA, Wassel AH, Benages A, Rodrigo JM. Predictors of morbidity and mortality after the first episode of upper gastrointestinal bleeding in liver cirrhosis. J Hepatol. 2000;32(1):19-24. [PubMed]

7. Chalasani N, Kahi C, Francois F, Pinto A, Marathe A, Bini EJ, et al. Improved patient survival after acute variceal bleeding: a multicenter, cohort study. The Am J Gastroenterol. 2003;98(3):653-9. [PubMed]
8. Ismail FW, Mumtaz K, Shah HA, Hamid S, Abbas Z, Abid $S$, et al. Factors predicting in-hospital mortality in patients with cirrhosis hospitalized with gastro-esophageal variceal hemorrhage. Indian J Gastroenterol. 2006;25(5):240. [PubMed]

9. Choi YJ, Kim JH, Koo JK, Lee CI, Lee JY, Yang JH, et al. Prevalence of renal dysfunction in patients with cirrhosis according to ADQI-IAC working party proposal. Clinical and molecular Hepatology. 2014;20(2):185-91. [PubMed | Full Text

10. Carbonell N, Pauwels A, Serfaty L, Fourdan O, Lévy VG, Poupon R. Improved survival after variceal bleeding in patients with cirrhosis over the past two decades. Hepatology. 2004;40(3):652-9. [PubMed | Full Text]

11. Reverter E, Tandon P, Augustin S, Turon F, Casu S, Bastiampillai R, et al. A MELD-based model to determine risk of mortality among patients with acute variceal bleeding. Gastroenterology. 2014;146(2):412-9. e3. [PubMed |Full Text]

12. Morsy ANMaKH. Scoring Systems and Risk Stratification in Cirrhotic Patients with Acute Variceal Bleeding "Scoring in Variceal Bleeding. J Liver. 2016;5(2). [Full text]

13. Mohammad AN, Morsy KH, Ali MA. Variceal bleeding in cirrhotic patients: What is the best prognostic score? Turk J Gastroenterol. 2016;27:464-9. [PubMed | Full Text] 